\title{
Profil dan Faktor yang Berhubungan dengan Masalah Perilaku pada Remaja di Kota Sorong Papua Barat
}

\author{
Dirgantari Pademme, Retno Sutomo, ${ }^{*}$ Lely Lusmilasari** \\ Magister Keperawatan, "Departemen Ilmu Kesehatan Anak Fakultas Kedokteran, Departemen Magister Keperawatan Universitas \\ Gadjah Mada Yogyakarta
}

\begin{abstract}
Latar belakang. Remaja dengan masalah perilaku memiliki kecenderungan melakukan perbuatan merusak atau merugikan bagi dirinya dan orang lain. Faktor terkait dengan masalah perilaku di antaranya jenis kelamin, usia, kedekatan dengan orang tua (hubungan dengan orang tua), keterlibatan orang tua dengan anak yang kurang dan pendidikan orang tua.

Tujuan. Mengetahui profil dan faktor yang berhubungan dengan masalah perilaku pada remaja di Kota Sorong Papua Barat.

Metode. Penelitian observasional analitik dengan rancangan cross sectional. Penelitian dilakukan pada bulan Maret-April 2017. Subjek penelitian berjumlah 566 orang siswa/i kelas X yang telah memenuhi kriteria inklusi yang dipilih secara simple random sampling. Instrumen yang digunakan adalah strength and difficulties questionairre (SDQ), Brief family relationship scale (BFRS) dan kuesioner demografi. Analisis data bivariat dengan chi-square dan analisis multivariat regresi logistik.

Hasil. Masalah perilaku pada aspek hubungan dengan teman sebaya abnormal 38,87\%, aspek emosional abnormal 25,80\%, conduct problems abnormal 24,38\%, hiperaktivitas abnormal 9,72\%, dan prososial abnormal 2,83\%. Analisis bivariat menunjukkan bahwa hanya keeratan hubungan antara orang tua dengan anak yang mempunyai hubungan bermakna dengan masalah perilaku keseluruhan, $\mathrm{p}=0,001(\mathrm{p}<0,05)$. Tidak terdapat hubungan yang bermakna antara jenis kelamin, tingkat pendidikan ayah, tingkat pendidikan ibu dan jumlah saudara dengan masalah perilaku keseluruhan $(\mathrm{p}>0,05)$. Analisis multivariat menunjukkan bahwa keeratan hubungan antara orang tua dengan anak yang berhubungan dengan masalah perilaku remaja di Kota Sorong $\left(\mathrm{OR}=2,67, \mathrm{CI} 95 \% 1,71-4,16, \mathrm{R}^{2}=0,03 \%\right)$. Kesimpulan. Terdapat hubungan keeratan antara orang tua dan anak dengan masalah perilaku remaja di Kota Sorong. Sari Pediatri 2017;19(4):189-95
\end{abstract}

Kata kunci: remaja, masalah perilaku, strength and difficulties questionairre (SDQ)

\section{Profile and Factors Associated with Behavioural Problem Adolescent in Sorong West Papua}

Dirgantari Pademme, Retno Sutomo, ${ }^{*}$ Lely Lusmilasari**

Background. Adolescents have a tendency to commit a destructive or harmful act towards themselves and others, such acts are called behavior problems. Factors associated with behavioral problems among adolescents including gender, age, and intimacy with their parents (parent-child relationship), a reduced engagement between parent and child.

Objective. To analyze profile and factors related with behavioral problem in Sorong, West Papua.

Methods. This research is an observational analytic research with a cross-sectional design. The study was conducted from March to April 2017. Subjects were 566 grade X students fulfilling the inclusion criteria. Sampling was done with simple random sampling methods. The instruments used are strength and difficulties questionnaire (SDQ), brief family relationship scale (BFRS) and demographic questionnaires. Analysis of bivariate data was done with Chi-square, and multivariate analysis with logistic regression.

Result. Behavioral problems with abnormal peer relationships were $38.87 \%$, abnormal emotional aspects of $25.80 \%$, abnormal conduct problems of $24.38 \%$, abnormal hyperactivity of $9.72 \%$, and abnormal pro socials of $2.83 \%$. Bivariate analysis showed that only close relationship between parent and child had significant relationship with overall behavior problem with $\mathrm{p}=0,001(\mathrm{p}<0,05)$. Gender, father's educational level, maternal education level and number of siblings have no significant relationship with overall behavioral problems $(p>0,05)$. Multivariate analysis showed that only close relationship between parent and child had significant relationship with overall behavior problem $\left(\mathrm{OR}=2,67\right.$, CI95\% 1,71-4,16, $\left.\mathrm{R}^{2}=0,03 \%\right)$.

Conclusions. There is a relationship between close relationship between parent-child with adolescent behavior problem in Sorong City. Sari Pediatri 2017;19(4):189-95

Keywords: adolescent, behavior problem, SDQ

Alamat korespondensi: Dirgantari Pademme. Fakultas Kedokteran Universitas Gadjah Mada, Yogyakarta, Indonesia. Jl. Kesehatan No. 1 Sekip Yogyakarta 55284. Email : dirgantari.pademme@gmail.com 
$\mathrm{R}$ emaja memiliki kecenderungan untuk melakukan perbuatan yang merusak atau merugikan bagi dirinya atau orang lain yang disebut dengan masalah perilaku. ${ }^{1}$ Masalah perilaku ditandai dengan pola tingkah laku antisosial, agresif atau menentang yang berulang dan menetap. ${ }^{2}$ Menurut kriteria diagnostic and statistical manual of mental disorder 5 (DSM-5), masalah perilaku merupakan bagian dari masalah emosi. ${ }^{3}$

Diagnosis kesehatan mental yang paling sering dan umum di antara anak dan remaja, yaitu disruptive behavior disorder (31\%) dan gangguan mood (21\%), tetapi $(40 \%)$ dari anak dan remaja dengan diagnosis kesehatan mental dianggap serius terganggu secara emosional. ${ }^{4}$ Masalah yang paling sering didiagnosis pada anak 6-17 tahun, yaitu gangguan belajar (11,5\%), attention-deficit/hyperactivity disorder $(8,8 \%)$, dan conduct disorder $(6,3 \%))^{5}$

Prevalensi masalah perilaku di New York pada rentang usia $10-16$ tahun sebesar $16 \%$ pada laki-laki dan $13 \%$ pada perempuan. ${ }^{6}$ Prevalensi keseluruhan masalah emosional dan perilaku di Tiongkok adalah 10,7\%. ${ }^{7}$ Penelitian yang dilakukan di Semarang tahun 2015 menunjukkan bahwa masalah yang dominan pada siswa-siswi remaja SMP dan SMA relatif sama dengan urutan masalah, yaitu perilaku agresif, cemas/ depresif, kesulitan memusatkan perhatian/konsentrasi, dan kesulitan dalam menjalin relasi dengan orang lain. ${ }^{8}$ Penelitian yang dilakukan di Aceh pada usia 6-12 tahun didapatkan masalah emosional $(37,8 \%)$, hiperaktivitas (27,3\%), conduct problem $(18,9 \%)$, dan masalah dengan teman sebaya $(16,1 \%){ }^{13}$

Faktor yang terkait dengan masalah perilaku pada remaja di antaranya adalah jenis kelamin, usia, kedekatan dengan orang tua (hubungan remaja dengan orang tua yang rendah), keterlibatan orang tua dengan anak yang berkurang 9 dan pendidikan orang tua. ${ }^{10,30}$ Penelitian menunjukkan bahwa anak laki-laki mengalami masalah perilaku lebih tinggi dibandingkan perempuan dan masalah perilaku cenderung menurun dengan usia. ${ }^{2}$

Peran perawat anak di komunitas dalam mengoptimalisasi perkembangan anak, salah satunya dengan memperhatikan kesehatan mental, adalah mengidentifikasi masalah kesehatan mental murid di sekolah. Perawat perlu melakukan upaya preventif berupa skrining, yaitu dengan melakukan kunjungan ke sekolah-sekolah dan melakukan assesment. ${ }^{11}$

Berdasarkan paparan di atas dapat disimpulkan bahwa remaja berisiko mengalami masalah perilaku yang dapat memberikan dampak jangka panjang, khususnya dalam hal perkembangan psikologisnya. Melihat belum banyak penelitian tentang masalah perilaku pada remaja di Indonesia dan belum ada penelitian yang mengulas tentang faktor yang berhubungan dengan masalah perilaku remaja di Papua Barat, maka peneliti tertarik untuk melakukan penelitian tentang profil dan faktor yang berhubungan dengan masalah perilaku pada remaja di Kota Sorong.

\section{Metode}

Penelitian ini merupakan penelitian observasional analitik dengan rancangan cross sectional. Sampel dimasukkan dalam penelitian bila memenuhi kriteria, yaitu siswa SMA kelas X dan bersedia menjadi subyek penelitian dengan menandatangani informed consent. Tidak ada kriteria eksklusi dalam penelitian ini. Sampel yang memenuhi kriteria inklusi berjumlah 566 orang. Teknik pengambilan sampel yaitu dengan purposive sampling untuk menentukan lokasi penelitian dan simple random sampling untuk menentukan responden penelitian. Penelitian ini menggunakan instrumen yang terdiri atas kuesioner demografi, kuesioner the brieffamily relationship scale (BFRS) untuk mengukur keeratan hubungan antara orang tua-anak dan strength and difficulties questionnaire (SDQ) yang diisi sendiri oleh remaja untuk mengukur masalah perilaku remaja. Pengambilan data mulai dilakukan pada tanggal 30 Maret-20 April 2017. Pengumpulan data dilakukan pada enam SMA di Kota Sorong. Peneliti dibantu oleh 2 orang asisten peneliti dengan kriteria lulusan Ners. Sebelum mengisi kuesioner, dilakukan pemilihan sampel dengan teknik simple random sampling berupa undian, dan bagi responden yang mendapat undian menjadi diikutkan dalam penelitian yang memenuhi kriteria inklusi. Setelah sampel penelitian terpilih maka dilakukan pengisian informed consent dan mengisi kuesioner secara lengkap. Data dianalisis dengan menggunakan software STATA versi 11.0. Analisis univariat meliputi data demografi, analisis bivariat digunakan uji chi-square dengan menghubungkan variabel keeratan hubungan antara orang tua dengan anak, jenis kelamin, tingkat pendidikan ayah, tingkat pendidikan ibu dan jumlah saudara dengan masalah perilaku remaja dan analisis multivariat menggunakan uji regresi logistik. 


\section{Hasil}

Keeratan hubungan antara orang tua dan anak yang baik $325(57,42 \%)$ orang. Lebih dari $50 \%$ subjek penelitian adalah perempuan, 367 (64,84\%) orang. Berdasarkan jumlah saudara, sebagian besar remaja memiliki saudara $\geq 2$ orang, 448 (79,15\%). Limapuluh persen ayah remaja berpendidikan SMA, yaitu $284(50,18 \%)$ orang. Demikian juga tingkat pendidikan ibu remaja terbanyak berpendidikan SMA, 277 (48,94\%) orang. Status perkawinan orang tua menunjukkan sebagian besar tidak cerai, 539 (95,23\%) orang.

Pada Tabel 2, subyek penelitian yang mempunyai proporsi tertinggi adalah pada hubungan dengan teman sebaya abnormal $38,87 \%$. Selanjutnya, proporsi tertinggi kedua pada masalah emosional abnormal $25,80 \%$. Urutan ketiga pada conduct problems abnormal $24,38 \%$, dan urutan keempat hiperaktivitas

Tabel 1. Distribusi frekuensi karakteristik subyek penelitian ( $\mathrm{n}=566)$

\begin{tabular}{lcc}
\hline Variabel & Frekuensi & $\%$ \\
\hline Jenis kelamin & & \\
$\quad$ Laki-laki & 199 & 35,16 \\
Perempuan & 367 & 64,84 \\
Jumlah saudara & & \\
$\leq 1$ & 118 & 20,85 \\
$\geq 2$ & 448 & 79,15 \\
Pendidikan ayah & & \\
Perguruan tinggi & 199 & 35,16 \\
SMA & 284 & 50,18 \\
SMP & 40 & 7,07 \\
SD & 36 & 6,36 \\
Tidak tamat SD & 7 & 1,24 \\
Pendidikan ibu & & \\
Perguruan tinggi & 160 & 28,27 \\
SMA & 277 & 48,94 \\
SMP & 56 & 9,89 \\
SD & 65 & 11,48 \\
Tidak tamat SD & 8 & 1,41 \\
Status perkawinan orang tua & & \\
Cerai & 27 & 4,77 \\
Tidak cerai & 539 & 95,23 \\
Keeratan hubungan antara orang & & \\
tua dan anak & & \\
Tidak baik & 241 & 42,58 \\
Baik & 325 & 57,42 \\
\hline
\end{tabular}

Tabel 2. Distribusi frekuensi masalah perilaku subyek penelitian berdasarkan SDQ $(\mathrm{n}=566)$

\begin{tabular}{lcc}
\hline Variabel & Frekuensi & $\%$ \\
\hline Masalah perilaku keseluruhan & & \\
$\quad$ Normal & 465 & 82,16 \\
$\quad$ Abnormal & 101 & 17,84 \\
Masalah emosional & & \\
$\quad$ Normal & 420 & 74,20 \\
$\quad$ Abnormal & 146 & 25,80 \\
Conduct problems & & \\
$\quad$ Normal & 428 & 75,62 \\
$\quad$ Abnormal & 138 & 24,38 \\
Hiperaktivitas & & \\
$\quad$ Normal & 511 & 90,28 \\
$\quad$ Abnormal & 55 & 9,72 \\
Masalah dengan teman sebaya & & \\
$\quad$ Normal & 346 & 61,13 \\
$\quad$ Abnormal & 220 & 38,87 \\
Perilaku pro-sosial & & \\
$\quad$ Normal & 550 & 97,17 \\
$\quad$ Abnormal & 16 & 2,83 \\
\hline
\end{tabular}

abnormal 9,72\%. Subyek penelitian menunjukkan perilaku prososial normal terbanyak $550(97,17 \%)$ orang.

Tabel 3 menunjukkan bahwa hanya variabel keeratan hubungan antara orang tua dan anak yang mempunyai hubungan yang bermakna dengan masalah perilaku keseluruhan remaja dengan nilai $\mathrm{p}=0,001$. Tabel 4 menunjukkan hubungan yang bermakna antara hubungan keeratan orang tua dan anak dengan masalah perilaku keseluruhan $\mathrm{OR}=2,67(\mathrm{CI} 95 \%=1,71-4,16)$.

\section{Pembahasan}

Proporsi terbesar masalah perilaku adalah hubungan dengan teman sebaya $(38,87 \%)$. Berbeda dengan Wiguna ${ }^{14}$ di Jakarta yang meneliti berdasarkan kelompok usia $\geq 12$ tahun, ditemukan proporsi terbesar adalah masalah emosional $(33,8 \%)$. Penggunaan waktu luang tanpa kegiatan banyak terjadi pada remaja di Kota Sorong sehingga sebagai bentuk mengisi kekosongan waktu mereka dengan bermain bersama teman sebaya. Adapun dalam membangun hubungan dengan teman sebaya, tentunya ada perbedaan pendapat, perbedaan nilai dalam kelompok yang dapat menimbukan ketidakmampuan untuk 
Dirgantari Pademme dkk: Profil dan faktor yang berhubungan dengan masalah perilaku pada remaja

Tabel 3. Analisis bivariat faktor yang berhubungan dengan masalah perilaku keseluruhan $(\mathrm{n}=566)$

\begin{tabular}{|c|c|c|c|c|c|c|c|c|c|}
\hline \multirow{3}{*}{ Variabel } & \multicolumn{6}{|c|}{ Masalah perilaku keseluruhan } & \multirow{3}{*}{$p$} & \multirow{3}{*}{$R P$} & \multirow{3}{*}{ CI95\% } \\
\hline & \multicolumn{2}{|c|}{ Abnormal } & \multicolumn{2}{|c|}{ Normal } & \multicolumn{2}{|c|}{ Total } & & & \\
\hline & $\mathrm{n}$ & $\%$ & $\mathrm{n}$ & $\%$ & $\mathrm{n}$ & $\%$ & & & \\
\hline \multicolumn{10}{|l|}{ Jenis kelamin } \\
\hline Perempuan & 29 & 14,6 & 170 & 85,4 & 199 & 100 & \multirow[t]{2}{*}{0,134} & \multirow[t]{2}{*}{1,06} & \multirow[t]{2}{*}{$0,98-1,14$} \\
\hline Laki-laki (R) & 72 & 19,6 & 295 & 80,4 & 367 & 100 & & & \\
\hline \multicolumn{10}{|l|}{ Tingkat pendidikan ayah } \\
\hline Tidak tamat SD-SMP & 13 & 15,7 & 70 & 84,3 & 83 & 100 & \multirow[t]{2}{*}{0,574} & \multirow[t]{2}{*}{0,96} & \multirow[t]{2}{*}{$0,87-1,07$} \\
\hline SMA-Perguruan Tinggi (R) & 88 & 18,2 & 395 & 81,8 & 483 & 100 & & & \\
\hline \multicolumn{10}{|l|}{ Tingkat pendidikan ibu } \\
\hline Tidak tamat SD-SMP & 82 & 18,8 & 355 & 81,2 & 437 & 100 & \multirow[t]{2}{*}{0,292} & \multirow[t]{2}{*}{0,95} & \multirow[t]{2}{*}{$0,87-1,03$} \\
\hline SMA-Perguruan Tinggi (R) & 19 & 14,7 & 110 & 85,3 & 129 & 100 & & & \\
\hline \multicolumn{10}{|l|}{ Jumlah saudara } \\
\hline$\geq 2$ & 86 & 19,2 & 362 & 80,8 & 448 & 100 & \multirow[t]{2}{*}{0,101} & \multirow[t]{2}{*}{1,08} & \multirow[t]{2}{*}{$0,99-1,17$} \\
\hline$\leq 1(\mathrm{R})$ & 15 & 12,7 & 103 & 87,3 & 118 & 100 & & & \\
\hline \multicolumn{10}{|c|}{$\begin{array}{l}\text { Keeratan hubungan antara orang } \\
\text { tua dan anak }\end{array}$} \\
\hline Tidak baik & 63 & 26,1 & 178 & 73,9 & 241 & 100 & \multirow[t]{2}{*}{$0,001^{*}$} & \multirow[t]{2}{*}{1,19} & \multirow[t]{2}{*}{$1,09-1,30$} \\
\hline Baik (R) & 38 & 11,7 & 287 & 88,3 & 325 & 100 & & & \\
\hline \multicolumn{10}{|l|}{ Status perkawinan orang tua } \\
\hline Bercerai & 7 & 25,9 & 20 & 74,1 & 27 & 100 & \multirow[t]{2}{*}{0,261} & \multirow[t]{2}{*}{0,89} & \multirow[t]{2}{*}{$0,71-1,12$} \\
\hline Tidak bercerai $(\mathrm{R})$ & 94 & 17,4 & 445 & 82,6 & 539 & 100 & & & \\
\hline
\end{tabular}

Keterangan :

$\mathrm{R}=$ reference/pembanding; $\mathrm{p}=\mathrm{p}$ value; $\mathrm{RP}=$ rasio prevalensi; $\mathrm{CI} 95 \%=$ confidence interval $95 \% ;{ }^{*}=$ signifikan $\mathrm{p}=<0,05$

Tabel 4. Analisis multivariat faktor yang berhubungan dengan masalah perilaku keseluruhan ( $\mathrm{n}=566)$

\begin{tabular}{|c|c|c|c|}
\hline Variabel & $\begin{array}{c}\text { Model } 1 \\
\text { OR (CI95\%) }\end{array}$ & $\begin{array}{c}\text { Model } 2 \\
\text { OR }(\text { CI95\%) }\end{array}$ & $\begin{array}{c}\text { Model } 3 \\
\text { OR }(\text { CI95\%) }\end{array}$ \\
\hline \multicolumn{4}{|c|}{ Keeratan hubungan antara orang tua dan anak } \\
\hline $\begin{array}{l}\text { Tidak baik } \\
\text { Baik(R) }\end{array}$ & $2,59(1,66-4,05) *$ & $2,62(1,67-4,09) *$ & $2,67(1,71-4,16) *$ \\
\hline Jumlah saudar & & & \\
\hline $\begin{array}{l}\geq 2 \\
\leq 1(\mathrm{R})\end{array}$ & $1,49(0,81-2,71)$ & $1,51(0.83-2,75)$ & \\
\hline $\begin{array}{c}\text { Jenis kelamin } \\
\text { Perempuan } \\
\text { Laki-laki(R) }\end{array}$ & $1,36(0,84-2,20)$ & & \\
\hline $\mathrm{N}$ & 566 & 566 & 566 \\
\hline Pseudo $\mathrm{R}^{2}$ & 0,04 & 0,04 & 0,03 \\
\hline
\end{tabular}

Keterangan : * $=$ signifikan $\mathrm{p}=<0,05$

melakukan penyesuaian dalam kelompok sehingga berujung pada konflik.

Penelitian kami menunjukkan masalah hubungan teman sebaya pada remaja perempuan lebih banyak $(46,1 \%)$ dibandingkan dengan remaja laki-laki
(25,6\%). Hasil penelitian kami serupa dengan penelitian Noakes ${ }^{15}$ yang melaporkan bahwa perempuan juga mengalami masalah dengan teman sebaya, yaitu terkait dengan adanya konflik. Emosi remaja perempuan yang memiliki konflik dengan kelompok 
sebaya akan terpengaruh. Hal tersebut disebabkan karena hubungan teman sebaya perempuan lebih eksklusif sehingga keintiman terjalin satu dengan yang lain dibandingkan dengan remaja laki-laki. ${ }^{16}$

Selain itu, remaja di Kota Sorong bergaul tidak hanya dengan sesama jenis kelamin, tetapi dengan berbeda jenis kelamin. Hal tersebut menyebabkan mereka terlibat dalam hubungan relasi berpacaran. Menurut Zimmer, ${ }^{17}$ selama masa remaja, hubungan dengan teman sebaya menjadi lebih intim dan mengalami peningkatan dalam menghabiskan penggunaan waktu berinteraksi dengan teman sebaya. Diperkirakan, remaja akan menghabiskan waktu luang mereka untuk mengembangkan hubungan romantis dengan lawan jenisnya. Konflik di antara teman sebaya sering terjadi pada remaja perempuan karena remaja perempuan banyak membentuk hubungan lintas gender. Remaja perempuan banyak terlibat dalam hubungan berpacaran yang berpotensi menyebabkan banyak konflik dengan teman sebaya atas perasaan persaingan, kecemburuan, dan ketidaksetiaan. ${ }^{18}$

Alasan lain yang menjadi kemungkinan penyebab masalah hubungan dengan teman sebaya di Kota Sorong adalah karena keeratan hubungan orang tua dan anak yang tidak baik. Kedekatan hubungan antara orang tua dan anak memiliki hubungan timbal balik dengan hubungan yang lain. ${ }^{19}$ Remaja yang kurang memiliki kedekatan dengan orang tua berdampak pada hubungan dengan yang lain, baik dengan teman sebaya maupun anggota keluarga lainnya. Hubungan baik yang dibangun orang tua dan anak memiliki pengaruh yang signifikan terhadap hubungan lainnya seperti hubungan dengan teman sebaya. ${ }^{20}$

Selain karena orang tua, dampak dari masalah dengan teman sebaya dapat memengaruhi masalah emosional remaja. Hasil penelitian kami mendapatkan proporsi tertinggi kedua adalah pada aspek emosional abnormal (25,80\%). Hal tersebut berbeda dengan penelitian Wang ${ }^{7}$ pada remaja yang berusia 15-18 tahun. Wang melaporkan masalah emosional $(\mathrm{m}=2,76$, $\mathrm{SD}=2,32)$, conduct problems $(\mathrm{m}=2,31, \mathrm{SD}=1,66)$, hiperaktivitas $(\mathrm{m}=3,19, \mathrm{SD}=2,13)$, masalah hubungan teman sebaya $(\mathrm{m}=3,01, \mathrm{SD}=1,60)$ dan perilaku prososial $(\mathrm{m}=7,68, \mathrm{SD}=2,12)$ yang menunjukkan bahwa prevalensi tertinggi pada masalah hiperaktif, urutan kedua pada masalah hubungan teman sebaya, dan urutan ketiga pada masalah emosional.

Shin $^{21}$ melaporkan bahwa remaja yang memiliki masalah dengan teman sebaya lebih mungkin menunjukkan masalah internalisasi. Perilaku internalisasi adalah perilaku yang mengarah pada diri sendiri, seperti kecemasan dan depresi. ${ }^{22}$ Emosi berperan penting dalam hubungan dengan teman sebaya. Remaja yang memiliki emosi yang berubahubah dan negatif akan mengalami penolakan yang lebih banyak oleh sebaya, sementara remaja yang memiliki emosi yang positif lebih diterima oleh sebaya. ${ }^{1}$

Menurut Finkenauer, ${ }^{22}$ masalah emosional pada remaja adalah stres. Salah satunya disebabkan karena keeratan orang tua yang digambarkan dalam pola asuh orang tua terhadap remaja. Keterlibatan orang tua yang kurang terhadap remaja menyebabkan penerimaan orang tua terhadap remaja kurang baik. Keterlibatan orang tua terhadap remaja diperlukan sehingga remaja menunjukkan keterbukaan kepada orang tua tentang masalahnya. Orang tua mengetahui yang dilakukan remaja dan orang tua memperlakukan remaja dengan baik ketika gagal di sekolah. ${ }^{23}$

Keeratan hubungan orang tua terhadap remaja di Kota Sorong menunjukkan persentase yang kurang baik. Hal tersebut memengaruhi penerimaan orang tua terhadap remaja di Kota Sorong. Keterbukaan remaja yang kurang terhadap orang tua disebabkan karena orang tua sering menyalahkan anaknya. Remaja merasa takut dan cemas ketika menceritakan masalah pribadi mereka dan kegagalan mereka di sekolah kepada orang tua. Penyebabnya karena orang tua cenderung mengatakan anak bodoh, sering membandingkan anaknya dengan anak tetangga lainnya dan menjatuhkan anak.

Hasil analisis univariat didapatkan proporsi conduct problems $24,38 \%$. Pada penelitian kami, data yang didapatkan dari kuesioner SDQ pada aspek conduct problems, yaitu sebagian responden $(44,88 \%)$ menjadi sangat marah dan sering tidak dapat mengendalikan kemarahan, 27,74\% menjawab agak benar bertengkar dengan orang lain serta memaksa orang lain melakukan apa yang diinginkan.

Pada masa remaja awal (12-15 tahun), terjadi peningkatan fluktuasi emosi dari tinggi ke rendah. ${ }^{1}$ Masa remaja merupakan masa transisi untuk mencapai identitas diri yang lebih stabil. Kematangan emosional remaja sangat dipengaruhi oleh kondisi lingkungannya, terutama lingkungan keluarga dan lingkungan sebaya. Kondisi lingkungan orang tua dan anak yang mengalami konflik menjadi salah satu sumber pengaruh conduct problem pada remaja. Remaja yang 
mengalami ketidaknyamanan emosional menimbulkan reaksi defensif sebagai upaya untuk melindungi kelemahan dalam dirinya. Remaja cenderung menunjukkan perilaku maladaptif, seperti agresif, melawan, keras kepala, bertengkar, berkelahi, dan sering mengganggu. ${ }^{24}$

Hasil hiperaktivitas abnormal pada remaja di Kota Sorong 9,72\%. Serupa dengan penelitian Wiguna ${ }^{14}$ di Jakarta yang melaporkan masalah hiperaktivitas $(6,25 \%)$ pada anak berusia $\geq 12$ tahun. Penelitian kami dan penelitian Wiguna sama-sama menunjukkan hiperaktivitas sebagai urutan terakhir dalam aspek masalah perilaku.

Menurut Babinski dan Lambert, ${ }^{25}$ hiperaktifimpulsif, kurang perhatian diprediksi menimbulkan perilaku menyimpang. Abikoff ${ }^{26}$ melaporkan bahwa anak yang mengalami hiperaktif-impulsif juga memiliki conduct problem. Hal tersebut serupa dengan penelitian Babinski dan Lambert ${ }^{25}$ yang melaporkan bahwa gejala hiperaktif-impulsif dan conduct problem berhubungan erat dan berisiko terhadap perilaku menyimpang pada usia dewasa.

Remaja di Kota Sorong sebagian besar memiliki perilaku prososial yang normal, meskipun memiliki masalah hubungan teman sebaya dan masalah emosional. Hal tersebut disebabkan kemungkinan jika di sekolah karena adanya harapan dari guru agar siswanya terlibat dalam tindakan prososial dan remaja takut akan hukuman dari guru. Alasan lain adalah harapan dari teman sebaya untuk memotivasi remaja berperilaku prososial supaya mencegah penolakan sosial dari teman sebaya. Sementara di rumah, remaja menunjukkan perilaku prososial dikarenakan harapan dari orang tua agar anaknya bisa memiliki empati terhadap orang lain. Remaja memiliki persepsi bahwa orang lain mengharapkan mereka berperilaku prososial sehingga hal tersebut memotivasi dalam berperilaku. ${ }^{27}$

Hasil penelitian kami menunjukkan hanya variabel keeratan hubungan antara orang tua dan anak yang mempunyai hubungan bermakna dengan masalah perilaku keseluruhan remaja. Hasil tersebut menunjukkan persamaan dengan penelitian yang dilakukan oleh Saputra ${ }^{13}$ yang melaporkan bahwa hubungan keluarga (orang tua dan anak) memiliki hubungan yang bermakna dengan masalah perilaku keseluruhan.

Remaja yang memiliki hubungan lebih dekat dengan orang tua akan memperoleh kehangatan yang cukup dan memengaruhi psikologisnya. ${ }^{29}$ Remaja yang memiliki kelekatan yang aman pada orang tua dalam masa remaja bisa membantu kompetensi sosial dan kesejahteraan remaja, seperti tercemin pada harga diri, penyesuaian emosional, dan kesehatan fisik. Remaja yang memiliki kelekatan dengan orang tua yang tinggi, kemungkinan rendah melakukan perilaku yang bermasalah. ${ }^{1}$

Hasil analisis multivariat menunjukkan variabel keeratan hubungan orang tua yang paling berhubungan dengan masalah perilaku keseluruhan remaja. Remaja yang memiliki hubungan lebih dekat dengan orang tua akan memperoleh kehangatan yang cukup dan memengaruhi psikologisnya. ${ }^{29}$

Kelebihan penelitian ini adalah penelitian pertama kali dilakukan di Papua Barat menyangkut masalah perilaku pada remaja. Adapun keterbatasan penelitian ini adalah menggunakan observasi dengan rancangan cross sectional untuk mengetahui masalah perilaku remaja.

\section{Kesimpulan}

Masalah perilaku pada remaja di Kota Sorong secara berurutan, yaitu masalah hubungan teman sebaya, masalah emosional, conduct problems, masalah hiperaktivitas dan gangguan prososial. Terdapat hubungan antara keeratan hubungan antara orang tua dan anak dengan masalah perilaku remaja di Kota Sorong, dan faktor yang paling berhubungan dengan masalah perilaku keseluruhan adalah keeratan hubungan orang tua dan anak

\section{Daftar pustaka}

1. Santrock JW. Perkembangan emosi masa remaja. Edisi ke-8. Jakarta: Penerbit Erlangga; 2007.

2. Liabo K, Richardson J. Conduct disorder and offending behavior in young people findings from research (child and adolescent mental health). London \& Philadelphia: Jessica Kingsley Publishers; 2007.

3. American Psychiatric Association. Diagnostic and statistical manual of mental disorder. Edisi ke-5. Washington, DC: APA; 2013

4. Mellin E. Responding to the crisis in children's mental health: Potential roles for the counseling profession. J Couns Dev 2009;87:501-6.

5. Blanchard LT, Gurka MJ, Blackman JA. Emotional, 
Dirgantari Pademme dkk: Profil dan faktor yang berhubungan dengan masalah perilaku pada remaja

developmental, and behavioral health of American children and their families: A report from the 2003 National Survey of Children's Health. Pediatrics 2006;117: e1202-12.

6. Murray J, Farrington DP. Risk factors for conduct disorder and delinquency: key findings from longitudinal studies. CanJ Psychiatry 2010;55::633-42.

7. Wang J, Liu L, Wang L. Prevalence and associated factors of emotional and behavioural problems in Chinese school adolescents : a cross-sectional survey. Child Care Health Dev 2014;40:319-6.

8. Ediati A. Profil emosi/perilaku pada remaja pelajar SMP-SMA di Kota Semarang. J Psikol UNDIP 2015;14:190-8.

9. NICE. Antisocial behavior and conduct disorder in children and young people : recognition, intervention and management. NICE clinical guidline 158. Diakses pada 8 Desember 2017. Didapat dari: https://www.nice.org.uk/guidance/cg158.

10. Zwaanswijk M, Verhaak PFM, Ende JVD, Bensing JM, Verhulst FC. Change in children's emotional and behavioural problems over a one-year period. Eur Child Adolesc Psychiatry 2006;15:127-31.

11. Shives LR. Concepts of psychiatric mental health nursing. Edisi ke-7. Lippincott Williams \& Wilkins; 2008.

12. Dinas Pendidikan Kota Sorong. Profil pendidikan Kota Sorong tahun 2016. Sorong 14 April 2017. Papua Barat; 2016.

13. Saputra F, Yunibhand J, Sukratul S. Relationship between personal, maternal, and familial factors with mental health problems in school-aged children in Aceh province Indonesia. Asian J Psychiatry 2016;25:207-12.

14. Wiguna T, Samuel P, Manengkei KPS, Pamela C, Rheza AM, Hapsari WA. Masalah emosi dan perilaku pada anak dan remaja di poliklinik jiwa anak dan remaja RSUPN dr. Ciptomangunkusumo (RSCM), Jakarta. Sari Pediatri 2010; 12:270-7.

15. Noakes MA, Rinaldi CM. Age and gender differences in peer conflict. J Youth Adoles 2006;35:881-91.

16. Azmitia M, Kamprath N, Linnet. Intimacy and conflict: the dynamics of boys' and girls' friendships during middle childhood and early adolescence. Dalam: Meyer LH, Park H, Grenot-Scheyer M, Schwarz IS, Harry B, penyunting. Making friends: the influences of culture and development .Baltimore: Paul H. Brookes Publishing Co; 1998.h.171-87.

17. Zimmer-Gembeck MJ. The development of romantic relationships and adaptions in the system of peer relationships. J Adoles Health 2002;31:216-25

18. Douvan E, Adelson J. The adolescent experience. New York: Wiley and Sons; 1966

19. Laursen, David W, Peter NB. Adolescent perceptions of reciprocity, authority, and closeness in relationships with mothers, fathers, and friends. Int J Behav Dev 2000:24: 46471.

20. Olivia A, Arranz E. Sibling relationships during adolescence. Eur J Dev Psychol 2005;2:253-70.

21. Shin KM, Cho S, Shin YM, Park KS. Effects of early childhood peer relationships on adolescent mental health: a 6-to 8-year follow-up study in South Korea Psychiatry Investig 2016:383-8.

22. Finkenauer C, Engels RCME, Baumeister RF. Parenting behaviour and adolescent behavioural and emotional problems: The role of self-control. Int J Behav Dev2005:29:5869.

23. Steinberg L, Lamborn SD, Darling N, Mounts NS, Dornbusch SM. Over-time changes in adjustment and competence among adolescents from authoritative, authoritarian, indulgent, and neglectful families. Child Dev 1994; 65:754-70.

24. Yusuf HS. Psikologi perkembangan anak dan remaja. Bandung: PT. Remaja Rosdakarya; 2009.

25. Babinski LM, Hartsough CS, Lambert NM. Childhood conduct problems, hyperactivity-impulsivity, and inattention as predictors of adult criminal activity. J Child Psychol and Psychiatry 1999;40:S002196309800362X.

26. Abikoff H, Courtney M, Pelham WE, Koplewicz HS. Teachers' ratings of disruptive behaviors: the infuence of halo effects. J Abnormal Child Psychol 1993;21:519-33.

27. Bandura A. Social foundations of thought and action: a social cognitive theory. Englewood Cliffs, NJ: PrenticeHall;1986.

28. De Goede IHA, de Branje SJT, de Delsing MJMH, Meeus WHJ. Linkages over time between adolescents' relationships with parents and friends. J Youth and Adoles 2009;38:1304-15.

29. Nash SG, McQueen A. Bray JH. Pathways to adolescent alcohol use: family environment, peer influence, and parental expectations. J Adoles Health 2005;37:19-28.

30. Huisman M, Araya, Lawlor R. Cognitif ability, parental sosioeconomic position and internalising and externalising problems in adolescence: findings from two European cohort studies. Eur J Epidemiol 2010;25:569-80. 